I SUSTENTABILIDADE • RISCO OU OPORTUNIDADE? 


\section{RISCO OU \\ OU \\ OPORTUNIDADE?}

| POR GUARANY OSÓRIO E INAIÊ TAKAES SANTOS

\section{Instrumentos para precificar emissões de gases de efeito estufa avançam no Brasil e no mundo. Falta usar o potencial nacional de produção industrial de baixa intensidade carbônica como diferencial competitivo.}

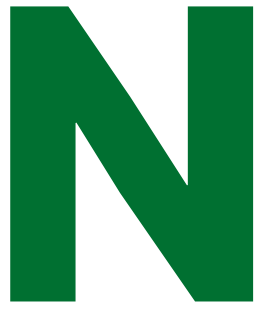

os últimos anos, observaram-se novos recordes de temperatura e aumento de eventos climáticos extremos, como ondas de calor e tempestades. Tanto indivíduos quanto grandes corporações já arcam com os prejuízos causados pelos impactos das mudanças no clima. Tais custos estão dispersos entre países, setores econômicos e famílias. Os que sofrem as consequências desses fenômenos não são necessariamente os mesmos que contribuem para que eles se acentuem. Esse descasamento entre quem arca com o custo e quem se beneficia das emissões faz com que haja um problema conhecido na economia como externalidade negativa ou, no contexto específico, como custo social do carbono que compreende os custos relacionados a danos provocados pelas emissões de gases do efeito estufa (GEE) no âmbito global pelo período em que esses gases permanecerem na atmosfera, trazidos a valor presente.

O problema pode ser contornado por meio da internalização desse custo no sistema de preços da economia para que as decisões de investimento, produção e consumo passem a considerá-lo de forma objetiva. Assim, a precificação de emissões de GEE, ou simplesmente precificação, busca tornar tangíveis os custos das emissões.

A precificação pode se dar por intermédio de uma tributação ou de um arranjo de mercado envolvendo a comercialização de permissões para emitir GEE, conhecido como sistemas de comércio de emissões. Em teoria, ambos os instrumentos são capazes de internalizar o custo social do carbono de forma efetiva.

\section{TENDÊNCIAS GLOBAIS}

A mudança do clima é um fenômeno global e não é simples promover essa internalização de custos de forma harmonizada entre todas as nações. Anteriormente a isso, é preciso mobilizar a vontade política de um número considerável de atores. Nesse sentido, o Acordo de Paris pode não ter trazido a solução para que a temperatura média global não aumente mais do que $2^{\circ} \mathrm{C}$ em relação aos níveis pré-industriais, mas estabeleceu um marco legal internacional para coordenar esforços de mitigação de emissões de GEE de 195 países. 


\section{RESUMO DE INICIATIVAS DE PRECIFICAÇÃO DE EMISSÕES IMPLEMENTADAS, PREVISTAS E EM ANÁLISE (SISTEMAS DE COMÉRCIO DE EMISSÕES E TRIBUTAÇÃO SOBRE EMISSÕES)}

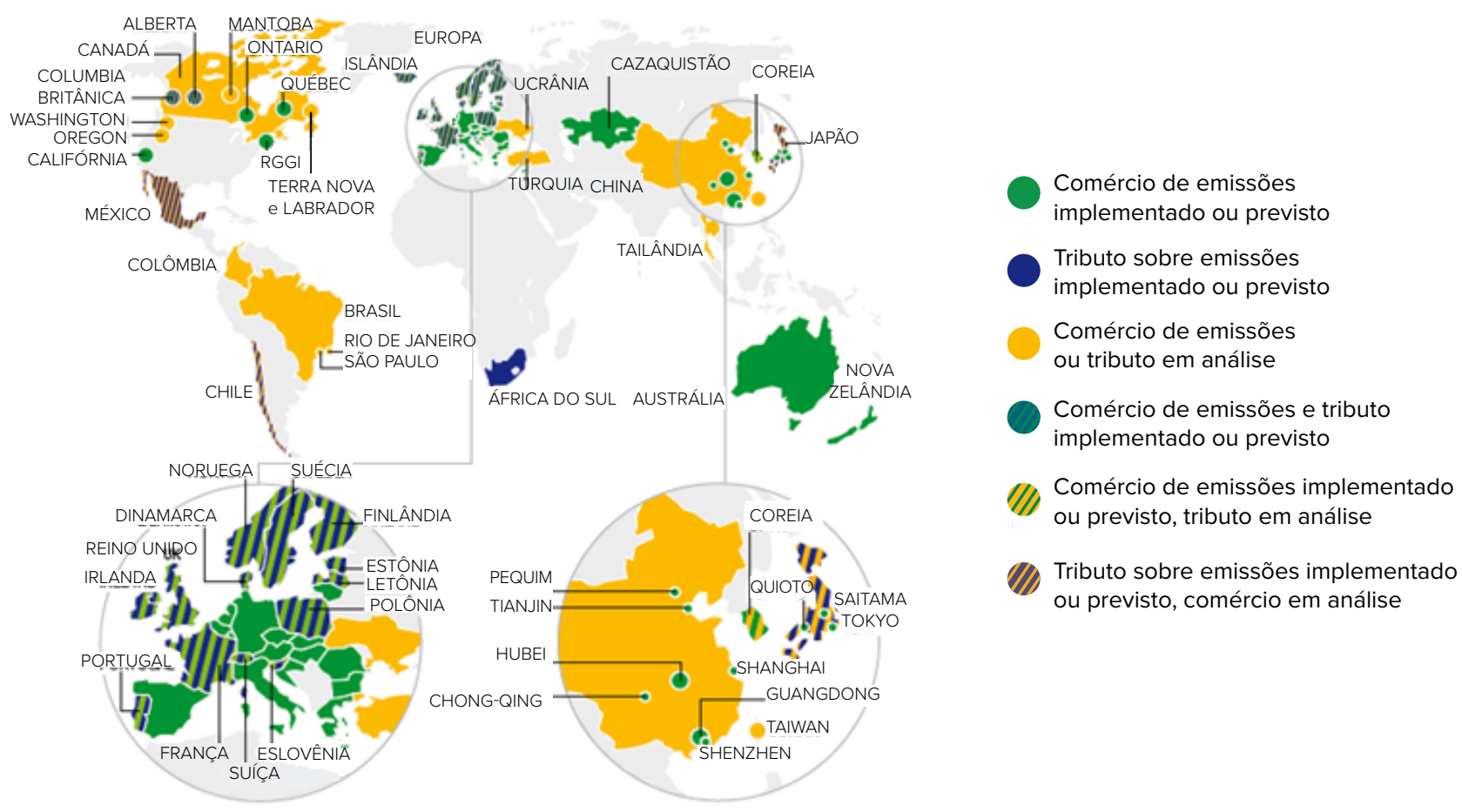

FONTE: WORLD BANK; ECOFYS; VIVID ECONOMICS, 2016. TRADUÇĀO DA LEGENDA FEITA PELOS AUTORES.

Uma questão fundamental para as partes signatárias diz respeito aos meios de implementação de suas contribuições ao acordo (Nationally Determined Contributions - NDCs). Para isso, há a possibilidade de transferência de resultados de mitigação entre países. Um país com custos de mitigação mais elevados adquiriria resultados de redução de emissões alcançados por países com custos inferiores, o que poderia ocorrer por meio de instrumentos de mercado. Mais de 100 países indicaram que planejam ou consideram fazer uso de instrumentos de precificação, cuja abrangência pode ser tanto doméstica quanto internacional.

Em muitos países, a mudança do clima e a regulação de emissões de GEE, particularmente, passaram a constituir um novo domínio de políticas públicas nas últimas duas décadas. Embora envolva desafios de natureza institucional e política, a adoção de instrumentos de precificação tem se disseminado inclusive entre países em desenvolvimento. Atualmente, mais de 40 países e 25 jurisdições subnacionais adotam algum instrumento de precificação de carbono, o que corresponde a aproximadamente $15 \%$ das emissões globais. A China, por exemplo, caminha em direção a um sistema de comércio de emissões de abrangência nacional que tem início previsto ainda em 2017, após cinco anos de operação com programas piloto em oito cidades e províncias.

No âmbito regional, a Aliança do Pacífico fortalece-se para avançar a implementação de instrumentos de precificação, pautada pelo objetivo dos governos do Chile, da Colômbia, do México e do Peru de promover o livre comércio na região. Na Declaração de Cali, assinada em junho passado, os presidentes desses quatro países reafirmam sua intenção de intensificar esforços em termos de mensuração, relato 


\section{Mais de 100 países dizem que planejam ou consideram fazer uso de instrumentos de precificação, cuja abrangência pode ser tanto doméstica quanto internacional.}

e verificação de emissões de GEE com vistas a identificar possíveis mecanismos voluntários de mercado na região.

Mundialmente, ainda, os economistas Joseph Stiglitz e Nicholas Stern, que lideram uma comissão para discutir o papel da precificação de carbono no enfrentamento do desafio climático, publicaram há poucos meses um relatório que traz uma mensagem bastante difundida nos livros-texto: a precificação é parte indispensável de qualquer estratégia que almeje reduzir emissões de forma eficiente. Entretanto a ênfase é menos na eficiência e mais no potencial que o instrumento tem de promover o crescimento econômico duradouro e sustentável, por exemplo, por meio de investimentos em novas tecnologias e infraestruturas relacionadas à baixa emissão de GEE.

A novidade está no patamar de preços capaz de direcionar os recursos necessários para atingirmos a neutralidade de emissões na metade deste século. Valores entre US\$ 40 e US\$ 80 por tonelada de $\mathrm{CO}_{2}$ em 2020 e algo entre US\$ 50 e US\$ 100 em 2030 seriam condizentes com os objetivos estabelecidos no acordo. Embora seja praticamente impossível imaginar um preço global para o carbono, a mensagem ecoa a urgência de se incorporar um sinal de preços nas políticas nacionais de mitigação da mudança do clima.

\section{NO BRASIL}

Nacionalmente, a Lei ${ }^{\circ} 12.187$, de 2009, instituiu a Política Nacional sobre Mudança do Clima (PNMC), designando um amplo conjunto de ações para atingir redução entre 36,1 e $38,9 \%$ das emissões brasileiras projetadas até 2020. Ainda que o artigo $9^{\circ}$ da referida lei mencione a criação do Mercado Brasileiro de Redução de Emissões (MBRE) para negociar títulos que representem emissões certificadas evitadas (e não direitos de emissão), até o presente não foi regulamentado nenhum instrumento que precifique as emissões de GEE diretamente.

Entretanto, há pelo menos cinco anos, uma equipe do Ministério da Fazenda vem analisando possíveis alternativas para apoiar a decisão do país sobre a adoção de um sinal de preços para as emissões de GEE. Atualmente, essa equipe coordena um conjunto de análises no âmbito do Projeto da Partnership for Market Readiness (PMR) no Brasil, que também conta com o apoio do Centro de Estudos em Sustentabilidade da FGV EAESP (GVces). A PMR é uma iniciativa global do Banco Mundial que apoia governos na formulação de políticas públicas de mitigação de emissões.

O objetivo da PMR Brasil é avaliar se é desejável que a PNMC contemple um instrumento de precificação e, em caso positivo, de que forma. O projeto chama a atenção para a pertinência de uma avaliação ampla, considerando a interação entre um conjunto de políticas setoriais e impactos econômicos da precificação no país. Essa avaliação integrada promove a coerência entre as políticas e o custo versus efetividade das reduções de emissões, evitando a adoção de medidas setoriais isoladas.

O cenário de restrição fiscal no setor público reforça a necessidade de identificação das fontes de financiamento para implementação da NDC do Brasil. Paralelamente, observa-se um movimento crescente de organizações no setor empresarial engajando-se em iniciativas relacionadas ao tema e produzindo análises detalhadas.

\section{ATUAÇÃO EMPRESARIAL NO BRASIL}

Embora muitas empresas já tenham experimentado elevação de custos de operação por conta da alteração de padrões climáticos ou eventos extremos, os custos reais da emissão de GEE ainda são invisíveis para os balanços financeiros corporativos. Buscando lidar com essa deficiência, algumas empresas passaram a adotar a precificação interna de carbono em suas estratégias, visando reduzir risco com investimento em ativos que podem ficar "encalhados", já levando em consideração a tendência internacional e a perspectiva da regulação de emissões via precificação se tornar realidade no Brasil. 


\section{RESPOSTAS ÀS PRINCIPAIS DÚVIDAS DOS GESTORES SOBRE A PRECIFICAÇÃO DE CARBONO}

1. Quais as implicações da precificação de carbono para as empresas?

Os insumos menos intensivos em emissões tornam-se relativamente mais baratos, favorecendo a substituição de combustíveis fósseis, por exemplo. Além disso, as tecnologias capazes de reduzir emissões ficam mais atrativas do ponto de vista financeiro.

2. Por que diversas empresas estão adotando precificação interna de carbono?

A adoção de um instrumento de precificação pode ser bastante complexa e requerer muita avaliação prévia, no entanto muitas empresas já consideram que isso será realidade mais cedo ou mais tarde. Para horizontes de planejamento financeiro e decisões de investimento que consideram anos ou décadas - e não meses -, seria imprudente considerar que as emissões de GEE continuarão a ter custo zero.

\section{As empresas terão suas vendas reduzidas por conta da precificação?}

Assim como ocorre com outras alterações de mercado, é possível que as vendas de determinados segmentos diminuam e outras aumentem. 0 resultado dependerá, sobretudo, da capacidade do produtor em substituir insumos e tecnologias e de repassar custos ao consumidor. Em última instância, se o consumidor optar por produtos alternativos que o satisfazem igualmente, haverá redução no volume de vendas de um lado e aumento de outro. A precificação favorece a emergência de produtos e tecnologias de baixo carbono, o que significa que é preciso estar atento não apenas para riscos, mas também para oportunidades.

De acordo com o relatório da organização CDP, que nasceu com o nome de Carbon Disclosure Project, em 2016, 47 empresas já adotam um preço interno de carbono ou pretendem fazê-lo nos próximos dois anos no Brasil. No ano passado também, o questionário do Índice de Sustentabilidade Empresarial (ISE) da bolsa de valores do Brasil (B3) passou a incorporar a pergunta sobre precificação interna, e a plataforma Empresas pelo Clima, do GVces, desenvolveu diretrizes para disseminar essa prática entre as empresas. Além disso, desde 2012, 35 empresas participam de uma simulação de sistema de comércio de emissões em conjunto com o GVces. Todas essas iniciativas apontam que o setor empresarial vem acumulando conhecimento e já é capaz de influenciar o debate, o que se reflete em posicionamentos como os publicados pelas Iniciativas Empresariais em Clima (IEC) e a Associação Brasileira da Indústria Química (ABIQUIM).

O Brasil tem enorme potencial comparativo de produção industrial, agrícola e energética com baixa intensidade carbônica, que na maior parte ainda não foi traduzido para diferencial competitivo. A precificação de emissões pode ser tratada pelas empresas como risco regulatório que elevará os custos de produção, ou como oportunidade para explorar um diferencial de competitividade. Tal distinção de percepções é crucial para que as empresas influenciem positivamente os processos que deverão definir em que momento e de que forma será implementado um instrumento de precificação no país. O desafio central reside em encontrar a melhor maneira de permitir que nosso potencial de contribuição ao acordo - e não apenas o que consta da NDC possa ser efetivamente explorado ao mesmo tempo em que fortalece a economia do país.

GUARANY OSÓRIO > Coordenador do Programa Política e Economia Ambienta (PEA) do GVces. Doutorando em Administração Pública e Governo pela FGV EAESP > guarany.osorio@fgv.br

INAIE TAKAES SANTOS > Pesquisadora do PEA/GVces da FGV EAESP >

inaie.santos@fgv.br
} 